\title{
CONFERÊNCIA
}

\section{A EPISTEMOLOGIA HOLISTA-INDIVIDUALISTA E O REPUBLICANISMO LIBERAL DE PHILIP PETTIT}

\author{
André Berten* \\ andre.berten@cpdr.ucl.ac.be
}

\section{Introdução}

É conhecido que um ponto central na noção de «republicanismo» consiste em defender uma interpretação da liberdade negativa diferente daquela dos liberais. A distinção entre a liberdade liberal como «não-interferência»e a liberdade republicana como «não-dominação» (Pocock, ${ }^{1}$ Skinner, ${ }^{2}$ Spitz, ${ }^{3}$ Sunstein, ${ }^{4}$ Pettit) ou como «não-interferência arbitrária», seria o que constitui a posição original de uma tradição republicana: nem liberalismo, nem comunitarismo, nem sequer humanismo cívico. A posição republicana recusa simultaneamente a liberdade negativa liberal e a liberdade positiva $\left(\right.$ Berlin $\left.^{5}\right)$, ou «liberdade dos antigos» $\left(\right.$ Constant $\left.^{6}\right)$, pois essas formas de valorização e de interpretação da liberdade tiveram conseqüências politicamente indesejáveis. Como diz Charles Larmore,

* Professor emérito da Universidade Católica de Lovaina, convidado a participar deste número da Kriterion.

POCOCK, 1975.

SKINNER, 1998

SPITZ, 1995.

SUNSTEIN, 1990.

BERLIN, 1969, p. 122-134.

CONSTANT, 1980[1819], p. 493-515.

KRITERION, Belo Horizonte, nº 115, Jun/2007, p. 9-31. 
(...) enquanto a idéia negativa de liberdade como ausência de interferência foi muitas vezes invocada para autorizar a criação de condições inumanas, particularmente no domínio econômico, o mau uso da idéia positiva levou historicamente mais longe e tornou a própria noção de liberdade sinônima de tirania, ao proclamar que o «higher self» do indivíduo era a Nação ou o Partido. ${ }^{7}$

Embora as teses republicanas pudessem aproximar-se de algumas teses de uma outra tradição republicana atual (aquela chamada de "humanismo cívico"), ou aproximar-se também, às vezes, das teses comunitaristas, ${ }^{8}$ trata-se, no entanto, de uma posição original, reivindicando outros modelos históricos. O republicanismo remete, através de Machiavelli e seus Discorsi sopra la prima deca di Tito Livio, mais ao pensamento político da Roma antiga do que à cidade grega. ${ }^{9}$

Como tradição consciente de si-mesmo, o liberalismo tem ao mais duzentos anos. Mas mais ou menos três séculos antes, a tradição política dominante na Europa e na América tinha insistido sobre a importância da liberdade e, na verdade, sobre a importância da liberdade negativa, tanto quanto o fizeram sempre os liberais. É a tradição republicana, moldada sobre o humanismo cívico da antiga Roma (..... ${ }^{10}$

Pettit usou vários termos para se referir a essa liberdade. ${ }^{11}$ Por exemplo, num artigo importante escrito com Braithwaite, aparece a tese de que o alvo de um regime republicano é a "maximização do 'dominion' das pessoas individuais" - poder-se-ia dizer "mestria". ${ }^{12}$ Em outros lugares, Pettit fala de "franquia": "Se a liberdade é construída como franquia, ela é compreendida de tal maneira que não há liberdade sem criação de um sistema de seguro mútuo de não-interferência entre os membros de uma sociedade."13

Eis uma citação que abrange vários temas e aspectos dessa liberdade:

7 LARMORE, 2004, p. 111.

8 Sobre essa diferença, ver: BERTEN, 2003. p. 21-36.

9 Sobre essa tradição, cf. os trabalhos de Newton Bignotto, entre outros: BIGNOTTO, 2001 e 2002.

10 BRAITHWAITE; PETTIT, 1990, p. 54. Pettit chama sua teoria de "neo-Romana", e não "neo-ateniana" (cf. para essa distinção: PETTIT, 1998, p. 73-96) - Hannah Arendt e Michael Sandel "têm a tendência de identificar a liberdade com a autonomia [self-rule] porque eles consideram a vida política, na qual os fins comuns são discutidos, decididos e executados, como o primeiro domínio no qual as virtudes são exercidas e o bem humano realizado» (LARMORE, a. c., p. 121). A teoria republicana de Pettit não é aquela do «autogoverno». Para ele - e é uma diferença essencial com o «humanismo cívico» -, a relação da democracia com a liberdade é aquela de um meio essencial, e não de uma «expressão privilegiada» dessa liberdade.

11 Às vezes, Pettit usa a terminologia dos "mundos possíveis" para introduzir as suas teses. Assim, definindo a liberdade, poder-se-ia dizer que ela é a ausência de interferência não somente no mundo real e atual, mas em todos os mundos possíveis pertinentes. Um escravo pode não sofrer interferência no mundo atual se o seu dono for benevolente, mas, num outro mundo próximo, esse dono poderia, arbitrariamente, interferir.

12 BRAITHWAITE; PETTIT, 1990, p. 54.

13 PETTIT, 1989, p. 160-161. 
A mestria [dominion] é liberdade, concebida de maneira holística: não a concepção liberal da liberdade como a condição do indíviduo atomístico, mas uma concepção republicana da liberdade como liberdade da cidade, liberdade num mundo social. A mestria é constituída pela posse de certos direitos e pela infra-estrutura de capacidade e de poder que esta implica. Crucialmente, ela contém um elemento subjetivo: para desfrutar de mestria, vocês devem saber que desfrutam de tudo aquilo que está implicado alhures (os direitos etc.) e isto de fato deve ser conhecimento comum. A mestria não é nada mais nem menos que a concepção republicana da cidadania. ${ }^{14}$

A não-interferência factual ou não-ingerência sempre defendida pelos liberais não é suficiente nem adequada. Um elemento central dessa diferença é a relação com a lei. A idéia liberal de não-interferência considera que toda lei é coerção e logo interferência. Mas a posição republicana sustenta que a lei não pode ser definida como invasão da liberdade, pois "pode dificilmente haver invasão de algo que não lhe preexiste". ${ }^{15}$

Como diz Skinner, Maquiavel

nos ensina que a lei pode agir para libertarnos de nossa mais autodestrutiva tendência natural a perseguirmos nossos interesses egoístas, forçando-nos antes em promover o interesse público num estilo originalmente virtuoso, e assim tornarnos capazes de preservar nossa própria liberdade individual antes de destruí-la. ${ }^{16}$

A tese de Skinner é de que se o aparelho da lei fosse recusado, não haveria um grau mais alto de liberdade pessoal com uma capacidade de usufruir dela sem risco, mas que, sendo dada nossa natureza potencialmente autodestrutiva, haveria antes uma diminuição da liberdade pessoal, e o perigo de cair numa condição de completa servidão.

Em outras palavras, antes da existência da lei, não se podia falar de liberdade no sentido republicano. Vê-se, aqui, uma crítica radical do modelo contratualista, isto é, da idéia de que o sistema social e político tem sua justificação na defesa de uma liberdade natural, preexistente. A concepção da liberdade de Pettit implica numa recusa das definições metafísicas. A liberdade é uma condição na qual nós nos encontramos. Ela não significa o controle que um indivíduo ou uma comunidade exerce sobre a forma de sua existência. Concepção "negativa" da liberdade porque nada é dito sobre o que deve ser feito com as possibilidades garantidas pela ausência de dominação. Concepção negativa porque não implica numa definição essencialista da 
liberdade. E, em particular, a liberdade como não-dominação não deve ser definida como autonomia racional nem como autogoverno democrático,

nem significa tampouco a atividade pela qual deveríamos realizar nossa verdadeira natureza ou dar expressão ao nosso ser mais alto [our higher self], que são as sortes de conclusões às quais as concepções positivas da liberdade tipicamente levam. Estar livre da dominação de um mestre não significa ser mestre de si-mesmo... ${ }^{17}$

Essa concepção da liberdade inscreve-se dentro do quadro geral do ideário "republicano" e não pode ser isolada desse quadro. Sem entrar aqui numa discussão das características do republicanismo - o que seria um tópico específico -, podemos defini-lo pelos traços seguintes: o termo "República" refere-se, geralmente, às características seguintes: uma forma de governo baseada na liberdade, uma lei não arbitrária, o estado de direito (rule of law), a independência do judiciário, direitos fundamentais que protegem a dignidade do indivíduo e a capacidade deliberativa de todos os cidadãos, um governo misto (com separação dos poderes, mas, geralmente, uma "dispersão" do poder, tal como o federalismo, a descentralização e os "checks and balances"). E, last but not least, uma característica talvez problemática: a "virtude cívica". A república se opõe simetricamente ao despotismo e à democracia direta. Portanto, a república deve ser um regime "representativo".

Voltarei à questão da liberdade republicana como "não-dominação". Eu gostaria, antes, de discutir o quadro teórico - epistemológico, metodológico - da obra explicitamente "republicana" de Philip Pettit, cujo Republicanism $(1997)^{18}$ apóia-se sobre um conjunto de argumentos que vai muito além das tradicionais teorias políticas. Esse livro está localizado entre duas obras que desempenham as bases antropológicas sobre as quais está construída a sua teoria republicana: The common mind (1993) ${ }^{19}$ e $A$ theory of freedom (2001). ${ }^{20}$

Minha questão é saber qual é o "sequitur" entre as concepções antropológicas e metodológicas de Pettit e sua defesa da forma específica de liberdade negativa dentro de um modelo republicano. Por isso, é preciso, 
em primeiro lugar, analisar os conceitos metodológicos utilizados, conceitos epistemológicos, psicológicos e sociológicos, isto é, conceitos defendidos por Pettit na sua versão da racionalidade própria às ciências humanas.

Segundo Pettit, uma teoria política deve apoiar-se sobre uma teoria social, e uma tal concepção, por sua vez, exige uma descrição do equipamento psicológico dos seres humanos. Isso significa que as descrições psicológicas determinam as condições de possibilidade (necessárias, embora não suficientes) do que pode e deve ser realizado nas partes superiores. Por exemplo, a distinção entre sistemas intencionais e sujeitos pensantes é uma distinção que determina quais são os sujeitos da ontologia social. A tentativa do livro The common mind, tentativa ambiciosa e profundamente original, é de articular uma psicologia inscrita no marco do cognitivismo atual com uma teoria normativa do político.

Segundo o próprio Pettit, as principais novidades de The common mind são:

1) A distinção entre sistemas intencionais que "crêem e desejam" e sistemas intencionais que "podem também pensar", ${ }^{21}$ isto é, sistemas intencionais que podem agir intencionalmente com uma concepção de suas crenças e de seus desejos que satisfaça a certos constrangimentos de racionalidade. É isso que acarreta uma distinção entre desejo e deliberação e a idéia de uma pertinência causal para dar conta dos estados intencionais. Os agentes são concebidos como "sistemas pensantes", como "sujeitos seguindo regras". ${ }^{22}$

2) A defesa de um "holismo individualista" ou de um "individualismo holista": a idéia que "sob algumas condições plausíveis, a capacidade de pensar exige a comunidade com os outros". ${ }^{23}$

Nessa perspectiva, Pettit introduz uma dupla distinção fundamental, original e, a meu modo de ver, correta: a distinção, primeiro, entre individualismo e atomismo; e, segundo, entre holismo e coletivismo. É a partir dessas oposições que ele defende um "individualismo holista". 


\section{Individualismo/coletivismo}

A primeira opçãoé para um “individualismo” metodológico (e psicológico) - e contra as formas sociológicas de coletivismo.

O individualismo significa que "a compreensão psicológica de senso comum, ou compreensão intencional sobre a qual nós baseamos nossa vida social" é considerada como "fundamentalmente válida. Somos tais que aparecemos a nós-mesmos". ${ }^{24}$ Somos "centros de pensamento, de sentimento e de ação" e "não peões ou brinquedos manipulados por forças coletivas". ${ }^{25}$

Essa compreensão corresponde às concepções da folk psychology defendidas na contemporânea philosophy of mind, isto é, à atribuição aos sujeitos humanos de uma "racionalidade mínima" que podemos deduzir de nossa capacidade de interpretar o comportamento de outrem e de prever (hipoteticamente) o seu comportamento futuro. ${ }^{26}$ Em outras palavras, é a atribuição a outrem das crenças e capacidades inferenciais mínimas que tornam possível um comportamento intencional. ${ }^{27}$ Isso implica, também, um privilégio do "consciente". Esse privilégio dado ao comportamento autoconsciente não significa uma negação das determinações sociológicas ou psicológicas: a afirmação da autonomia do indivíduo não implica na negação das determinações sociais da mesma maneira que a afirmação do caráter intencional de nossas ações não nega a eventual determinação inconsciente. $\mathrm{O}$ anticoletivismo, correspondendo a essa posição, significa, negativamente, que não se pode reduzir a explicação do comportamento a determinações externas, quaisquer que sejam, ${ }^{28}$ e, positivamente, que a interpretação da ação humana pressupõe, como sua condição de possibilidade, uma racionalidade mínima.

Essa primeira afirmação repousa sobre "uma distinção que é tão óbvia que depois de considerada pode-se apenas ficar admirado que ela pudesse ter sido neglicenciada durante tanto tempo por tantos filosófos". ${ }^{29}$ É a distinção entre sistemas intencionais e sujeitos pensantes. Os sistemas intencionais são sistemas que manifestam regularidades racionais nas suas interações com o seu meio ambiente, que realizam um certo grau de racionalidade do

24 PETTIT, 2004. p. 3.

25 Idem.

26 Cf. por exemplo: BOGDAN, 1991 e 1997. Pettit assimila essa capacidade de interpretação ao Verstehen, oposto ao Erklären, à explicação geralmente admitida na ciência.

27 É a aplicação do "princípio de caridade" na interpretação: mostrar quais são as competências mínimas que se devem atribuir aos interlocutores para que seja possível uma compreensão mútua. Cf. QUINE, 1999, p. 73-79.

$28 \mathrm{E}$, talvez, mais pragmaticamente, que não é possível coordenar - globalmente - a nossa ação com a do outro sobre uma outra base.

29 BRANSEN, 1994, p. 2. 
fato de terem crenças e desejos - e pode-se atribuir essas características aos sistemas animais, pelo menos aos animais evoluídos. Os sujeitos pensantes são sistemas intencionais que, além disso, não somente realizam um certo grau de racionalidade no seu comportamento, mas também têm atitudes reflexivas a respeito dos conteúdos de suas crenças e de seus desejos. Os sujeitos pensantes podem cuidar da racionalidade de suas crenças e de seus desejos, lutar intencionalmente para aumentar a racionalidade das crenças e dos desejos..$^{30}$ Essa reflexividade tem uma conseqüência essencial: os sujeitos pensantes são capazes de tratar alguns desses conteúdos de crença e desejo como constrangimentos normativos, como regras de pensamento que eles são capazes de seguir e, eventualmente, de transgredir.

Essa definição do individualismo é uma tese contra as várias formas daquilo que Pettit chama de «coletivismo». ${ }^{31}$ Nossa autarquia intencional pode ser parcialmente determinada pelas regularidades (neurofisiológicas) mais básicas. ${ }^{32}$ Ela pode ser comprometida pela nossa dependência das regularidades sociais. Estas podem, em certos casos, ser mais potentes que as regularidades intencionais (the overriding thesis). Elas podem também constituir uma ordem mais profunda dentro da qual as regularidades intencionais estão atualizadas (the outflanking thesis). ${ }^{33}$

A questão, contudo, é saber se a existência de coletivos invalida nossa descrição de nós mesmos como sendo sujeitos mais ou menos autônomos, intencionais, pensantes, que se preocupam com a racionalidade de suas crenças e seus desejos. Para tratar dessa questão, é necessário dizer o que são esses "coletivos". Pettit os identifica de maneira formal a partir das regularidades sociais, estruturais, e das relações dessas regularidades com as regularidades intencionais. Há regularidades características das crenças e desejos, regularidades que ditam o efeito de certos tipos de evidências sobre as quais crenças e desejos estão mantidos, e que ditam o efeito de certos tipos de perfis de crenças-desejos a partir dos quais certas responsabilidades estão afastadas. Os agentes interagem com seu meio ambiente sob o controle

30 É o que Pettit chama de "intentional ascent".

31 O que muitas vezes nas ciências sociais é chamado de "holismo": "O que é mais freqüentemente chamado de holismo na literatura é uma concepção das relações entre os agentes e suas propriedades e interrelações, de um lado, e as macropropriedades (os "todos" sociais, como grupos, propriedades de grupo ou estruturas sociais). Esse debate Pettit o chama de debate individualismo-coletivismo." (TUOMELA, 1994, p. 306-321)

32 Como, do ponto explicativo, o sustentam os "eliminativistas". Cf. por exemplo: CHURCHLAND, p. 67-90, 1981; e CHURCHLAND, 1989.

33 Cf. PAPRZYCKA, 1998, p. 165. 
das regularidades intencionais (enquanto os agentes não intencionais não interagem dessa maneira).

Essa abordagem me parece essencial porque permite uma confrontação de grandezas comparáveis - o que não seria o caso, por exemplo, se tivesse que comparar as "intenções" com as "estruturas" sociais. Nessa perspectiva, é claro que as regularidades sociais, estruturais, podem superar (overriding, overruling, outflanking) as regularidades intencionais. Mas Pettit sustenta que o socialestrutural não destrói o intencional, mas - utilizando um conceito da filosofia da mente - "supervem" sobre este último. As regularidades socioestruturais (do tipo durkheimiano) - por exemplo: "o desemprego aumenta a criminalidade" -, regularidades que são "causalmente e logicamente descontínuas" em relação às regularidades intencionais da psicologia individual, supervêm sobre as regularidades intencionais, mas não as eliminam.

O individualismo de Pettit não defende a idéia de que o "indivíduo" seria "singular". Pelo contrário: o que permite interpretar "racionalmente" o outro é o fato de que sua ação obedece a regularidades - análogas a tipos-ideais weberianos. Afirma somente que há dois tipos de regularidades diferentes. O coletivismo "afirma que as regularidades coletivas escondidas da história e da sociologia que existem para serem desveladas na procura do Erklären científico são mais importantes que as regularidades familiares associadas à compreensão ordinária de si - ao Verstehen, como se diz às vezes". ${ }^{34}$ Mas essas últimas regularidades "intencionais" ficam relativamente independentes das regularidades sociais. O argumento é o seguinte: "O sujeito intencional é o único que conhecemos e, apesar de tudo o que as ciências históricas e sociais parecem capazes de mostrar, é o único que temos a probabilidade de encontrar no decurso de nosso esforço de reflexão sobre nós mesmos e nossa vida compartilhada." 35

Isso implica numa tese sobre o que é "explicar", pois a explicação nas ciências sociais deve levar em conta o status ontológico dos atores. Pettit remete aqui a David Lewis: "Segundo Lewis, explicar um acontecimento é fornecer informação sobre a sua história causal." ${ }^{36}$ Com efeito, para justificar uma interpretação das relações sociais e da ação política, é preciso oferecer também uma concepção plausível das cadeias causais que dizem respeito ao curso temporal dos acontecimentos. Pettit defende uma teoria inferencial, ${ }^{37}$ teoria 
conectada com a tradição hermenêutica. Isso significa que as propriedades causalmente pertinentes são as crenças e os desejos, mas também

percepções caracterizadas proposicionalmente e crenças caracterizadas proposicionalmente, no mesmo tempo que hábitos de inferência implicados no movimento que vai das percepções às crenças e das crenças a outras crenças, e também com os desejos implicados no movimento que vai das crenças às ações. ${ }^{38}$

Note-se que o estilo interpretativo e reconstrutivo proposto por Pettit é o modo normal, ordinário, de explicação que utilizamos diariamente para compreender os comportamentos dos outros e os acontecimentos sociais (Verstehen). E, na verdade, é o tipo de explicação que se encontra também em muitos estudos sociológicos, históricos e etnológicos, modelo muito próximo daquele do individualismo metodológico de Max Weber. ${ }^{39}$ Isso não significa uma desconsideração de outros modos de explicação "por programação", "normativas" ou "interpretativas", ${ }^{40}$ mas a tese de que, nas práticas - sociais, culturais, políticas -, o modo ordinário de compreensão não pode ser negligenciado.

\section{Holismo/atomismo}

A primeira distinção é "vertical". A segunda distinção - atomismo/ holismo - é "horizontal" e diz respeito à questão de se os indivíduos podem exercer suas capacidades independentemente das relações sociais dentro das quais estão imersos. Pettit defende aqui a tese de que as relações sociais são necessárias para a emergência e a persistência de propriedades distintivas e importantes desses indivíduos. A propriedade de ser um sujeito pensante exige a presença de relações sociais. É verdade que a capacidade de pensar é uma

38 PETTIT, 1997, p. 234.

39 É também o que, quase de maneira inata, compõe as competências cognitivas das crianças. Cf. WELLMAN, 1990.

40 Pettit defende o que ele chama de um ecumenismo explicativo. Em função das características específicas de um fenômeno que queremos explicar, podemos, entre as explicações racionais, dar mais peso às explicações de tipo «programming», «normalising», «interpretative» (cf. PETTIT, 2004, p. 19 et seq.). Cf. também o «program model» elaborado por Pettit e Jackson (JACKSON; PETTIT, 1990). Segundo esse modelo, todo antecedente que, a qualquer nível, supervem sobre o nível físico fundamental pode ser causalmente pertinente para um fenômeno que queremos explicar; porque este "programa para" uma organização adequada está acima do nível fundamental que causará a realização do fenômeno. No «ecumenismo» explicativo, Pettit mostra também que o comportamento pode ser compreendido sob o modelo do Verstehen na maioria dos tempos, mas que a racionalidade «utilitarista» ou «economista» fica sempre, por assim dizer, em stand by, podendo manifestar-se em circunstâncias extraordinárias; a explicação «funcionalista» aparece também como um instrumento importante de compreensão (ou de explicação). 
capacidade individual, a capacidade de um sistema intencional individual. Mas vimos que o sujeito capaz de ascensão [ascent] intencional, capaz de reflexividade, é também capaz de seguir regras. Em outras palavras, ele deve ter uma capacidade normativa. Ora, como Wittgenstein o mostrou, seguir regras não pode ser uma atividade privada. Portanto, há necessariamente um aspecto essencial da atividade intencional que deve ser considerada de um ponto de vista holista.

A descrição da constituição dos sujeitos pensantes que emerge dessa explicação de seguir uma regra sustenta e exige uma ontologia social particular: o "individualismo holístico", a dependência constitutiva do pensar humano para com as relações. Essa dependência implica numa negação do atomismo, ${ }^{41}$ mas não do individualismo:

Não penso que os seres humanos dependem somente de si-mesmo, ou pelo menos que seja o caso num sentido evidente. Estimo no entanto que o individualismo ou o humanismo têm razão em insistir sobre o fato de que a libertação fundamental que traz o Verstehen ainda não foi falsificada nem transcendentada. ${ }^{42}$

Recusar o coletivismo e defender o individualismo não implica, portanto, uma concepção "atomista". Pelo contrário, Pettit afirma que "os individuos dependem de maneira constitutiva ou não causal de suas relações com os outros para a possessão de uma capacidade humana particularmente importante": eles "dependem uns dos outros para serem capazes de raciocinar e pensar individualmente". ${ }^{43} \mathrm{O}$ holismo permite dizer que a sociedade precede a individualidade, que ela é uma precondição da individualidade. O que está afirmado aqui é que nenhum indivíduo é capaz de manifestar, por ele mesmo, uma psicologia humana completa. Desenvolver comportamentos intencionais e, sobretudo, reflexivos é uma coisa que as pessoas apenas podem realizar nas suas relações com os outros. "Essa tese, diz Pettit, é perfeitamente compatível com a afirmação segundo a qual a psicologia produzida graças às relações com os outros é justamente o tipo de psicologia em que acreditam os individualistas." ${ }^{44}$ Ela visa a interpretar o fato de que, pelo menos na modernidade, a autoconsciência individualista não é uma mera ilusão.

41 Negação também do "singularismo", tese defendida por Quinton (e, aliás, muitos outros, eu inclusive), dizendo que as entitades sociais (instituições, organizações, grupos etc.) não podem ser consideradas como realidades "intencionais".

42 PETTIT, 2004, p. 5.

43 Ibidem, p. 7.

44 Idem. 
O holismo aqui defendido significa que existem algumas - talvez muitas - propriedades individuais que não podem existir fora de uma sociedade, de relações sociais. Por exemplo, o estatuto e o poder que alguém possui numa sociedade dependem do fato de que os outros têm algumas crenças sobre o estatuto e o poder. Nesse sentido, se trata de uma propriedade intrinsecamente social: um indivíduo solitário não poderia desfrutar de um estatuto e de um poder. Mas não são esses tipos de dependência (evidentes e que ninguém pode negar) que definem o holismo de Pettit. A sua tese é muito mais sutil. É na constituição mesma da individualidade que a dependência dos outros se revela essencial. É essa tese que fundamenta a crítica da concepção "liberal" da liberdade tanto quanto das teorias contratualistas, partindo da ficção de um indivíduo radicalmente isolado.

Pois bem, essa reflexividade é possível somente porque os seres humanos são dotados de linguagem. ${ }^{45}$ As atitudes reflexivas, secundárias, não podem ser adotadas pelos membros de uma comunidade lingüística. Ou, formulado de maneira diferente, o "pensamento", a reflexividade, pressupõe o uso da linguagem; isso pressupõe a capacidade de seguir regras, e seguir regras é possível apenas para uma criatura social. A relação com a comunidade é, portanto, constitutiva do pensamento mesmo.

\section{Indeterminação, common knowledge, equilíbrio reflexivo}

A interpretação intencional do comportamento humano e o holismo individualista têm uma consequiência epistemológica crucial: a tese da relativa indeterminação da interpretação. A perspectiva intencional - que implica a necessidade da interpretação do comportamento dos outros - dá lugar a uma indeterminação sobre os conteúdos que devem ser atribuídos aos estados intencionais. Da mesma maneira, a questão clássica, wittgensteiniana - "o que é seguir uma regra?" -, implica também uma forma de indeterminação. As regras "são coerções normativas que determinam que um item - ou talvez um subconjunto - de um conjunto de opções é mais apropriado de uma certa maneira que as alternativas". ${ }^{46}$ Mas as regras são pertinentes numa variedade indefinidamente grande de situações e não existem metaregras para aplicação

$45 \mathrm{Ou}$, pelo menos, de produzir intencionalmente "signos" para expressar o pensamento.

46 PETTIT, 1997, p. 65. Essa exigência de "common knowledge" pode ser entendida como exigência de "publicidade", tal como é formulada por Rawls: a idéia de "publicidade" implica que "a sociedade é efetivamente regulada por princípios públicos de justiça: os cidadãos aceitam e sabem que os outros também aceitam esses princípios, e essa percepção, por sua vez, é publicamente reconhecida" (RAWLS, 2000. p. 110). 
das regras. Isso significa que não há uma maneira efetiva e mecânica de especificar os conjuntos de opções às quais elas se aplicam. As regras são "open-textured".

Há uma correlação entre hábitos, inclinações e regras. Quando as circunstâncias são favoráveis (normais), há uma conexão entre inclinação e regra. Mas "desde que nunca podemos saber de antemão que nossas circunstâncias são normais ou ideais, isto significa que as regras são apenas legíveis de maneira falível para sujeitos finitos como nós. O êxito de nossa intenção de seguir uma regra é uma realização que podemos apenas avaliar $a$ posteriori". ${ }^{47}$

Por outro lado, a concepção intencionalista dos estados de consciência implica, como o vimos, na tese do caráter consciente dos desejos, pensamentos etc. Mas o holismo, por sua vez, implica que a autoconsciência, como forma de pensamento reflexivo, não pode constituir-se sem relação com as opiniões dos outros. Assim, por exemplo, se a liberdade como não-dominação pode ser considerada como um elemento importante das reivindicações dos cidadãos das sociedades modernas, é preciso também que haja "consciência" da liberdade, e que essa consciência seja reconhecida.

(...) segundo a explicação holista, a perfeita fruição da liberdade parece também exigir que a consciência dessa fruição esteja compartilhada com as outras pessoas na comunidade, de tal maneira que seja de conhecimento comum que ela desfruta de uma ausência de coerção assegurada corretamente. ${ }^{48}$

Sabemos que a plena liberdade, como a dignidade ou a autoridade, é algo que uma pessoa pode possuir somente na medida em que ela tem um certo status em relação aos outros. Ora, essa consideração epistemologico-psicológica tem imediatamente uma consequiência importante no nível político: ela implica a igualdade. A liberdade, ou "dominion" é

o status social do qual você desfruta perfeitamente quando a sua perspectiva de liberdade não é menor que aquela de qualquer outro na sua sociedade e quando é de saber comum entre você e os outros que é o caso. A única qualificação é que se você e seus concidadãos estão todos equipados para desfrutar dessa mestria, sendo iguais com respeito a ela, devem ter as mais amplas perspectivas de liberdade compatíveis com essa igualdade (...). ${ }^{49}$

47 BRANSEN, 1994, p. 3.

48 BRAITHWAITE; PETTIT, 1990, p. 64.

49 Ibidem, p. 85. 
É por isso que se pode dizer que uma pessoa desfruta de uma plena liberdade se ela desfruta de uma perspectiva de liberdade que não é menor que aquela que está disponível para os outros cidadãos - princípio de igualdade - e que

é de saber comum entre os cidadãos que essa condição tem a prevalência, de tal maneira que essa pessoa e quase todas as outras pessoas sabem que ela desfruta da perspectiva mencionada, que ela e quase todas as outras pessoas sabem que as outras geralmente sabem isso também, e assim por diante..$^{50}$

A tese do common knowledge vem, como se sabe, de Lewis. ${ }^{51}$ Em Pettit, ela é uma maneira de superar a indeterminação pelo apelo à publicidade. ${ }^{52}$ Politicamente, ela corresponde à tese da razão pública em Rawls. ${ }^{53}$ Há, assim, no meu modo de ver, uma circularidade. Partindo de uma descrição do funcionamento cognitivo dos sujeitos pensantes, há conseqüências sociais e políticas. Mas, por outro lado, para dar conta dos princípios normativos atualmente em vigor nas democracias modernas, há de pressupor o tipo de funcionamento psicológico aqui descrito.

Poderíamos dizer que, desse ponto de vista, a atitude de Pettit é "pósmetafísica": pragmática, empirista e conseqüencialista. As avaliações práticas são ligadas à indeterminação dos conteúdos semânticos das normas e das intenções (as primeiras ligadas às interpretações das segundas). É nesse sentido que Pettit aprova, nas questões práticas, o método do equilíbrio reflexivo de Rawls. A indeterminação intencional e a aceitação do common knowledge proíbe, com efeito, uma forma de teoria ética universalista e dedutiva - tipo deontológica, ${ }^{54}$ Pettit sugere, antes, que a abordagem da política pode basearse na reconstrução dos axiomas pressupostos na formação dos juízos sobre questões institucionais particulares. Mas os axiomas não precisam representar uma base única de justificação, como num esquema fundacionalista. Eles constituem, antes, um simples ponto de partida para organizar as intuições.

50 BRAITHWAITE; PETTIT, 1990, 64-65.

51 LEWIS, 1969.

52 Essa sugestão mereceria uma discussão detalhada, entre outros, para mostrar que o common knowledge é um tipo de «princípio ponte» entre as investigaçãos comunicativas e as teses políticas.

53 RAWLS, 2000.

54 É por isso também que a utilização do equilíbrio reflexivo não acarreta uma aceitação do deontologismo da Teoria da justiça de Rawls. É verdade que o deontologismo rawlsiano, inscrito na prioridade lexical absoluta do primeiro princípio de justiça, é, contudo, um deontologismo moderado na medida em que esse primeiro princípio diz respeito a um conjunto de liberdades das quais nenhuma pode ser considerada como absoluta, um deontologismo também matizado pelo equilíbrio reflexivo, mesmo que este não pareça poder derrubar os princípios de justiça. 
Toda abordagem desse tipo deve portanto ser julgada sobre duas frentes: de um lado, em função do caráter atrativo do axioma ou dos axiomas em si mesmos e do papel organizacional que lhes está atribuído; por outro lado, em função da plausibilidade e da adequação dos teoremas que são derivados desses axiomas. Essa concepção concorda com o método do equilíbrio reflexivo de Rawls. ${ }^{55}$

Para Rawls, a posição de Pettit se justifica pelo benefício que ela pode trazer às teses políticas. Assim, o método adotado mostra a sua originalidade, pois ele permite recusar um liberalismo que tentaria construir uma teoria da justiça baseada sobre princípios deontológicos lexicalmente ordenados e de recusar também uma forma de utilitarismo baseado na maximização da satisfação das preferências. A teoria de Pettit é consequiencialista (não deontológica) no sentido de que se a liberdade como não-dominação é um "bem", e um bem que deve ser maximizado, ela não pode ser considerada como um valor absoluto, uma vez que a sua maximização implica às vezes o seu não respeito (parcial ou provisório, como a maximização da paz pode implicar em certas circunstâncias de fazer a guerra ${ }^{56}$ ).

No que diz respeito à concepção conseqüencialista da liberdade como não-dominação, "o teste pertinente, aqui como em outros aspectos da teoria política, é o do equilíbrio reflexivo" ${ }^{57}$ Essa perspectiva significa que a liberdade como não-dominação não é o "bem supremo", o "sumo bem" (entendido num sentido deontológico, ou em valor). É uma crítica que se pode fazer a algumas formas do liberalismo quando afirma que a liberdade (como não interferência) é o valor supremo.

O importante aqui é compreender que as posições axiológicas defendidas por Pettit são as mais coerentes, uma vez que se aceita a descrição psicológica intencional ligada à filosofia da mente adotada em The common mind $\mathrm{e}$ nas outras obras do autor. O holismo individualista permite distinguir, por exemplo, entre desejo e deliberação. O contexto da folk psychology, e das interpretações em termos de crenças e desejos, permite entender a crítica de um utilitarismo simples e justificar uma diferença importante entre um sistema político concebido como devendo favorecer a satisfação máxima das preferências - que ficam no nível abstrato de uma racionalidade intencional, isto é, dos desejos considerados como dados - e uma forma "deliberativa" de

55 PETTIT, 1997, p. 11.

56 Pettit toma o exemplo do pacifista radical que era Bertrand Russell, que, quando da primeira guerra mundial, enfrentou a prisão por suas posições antiguerra, mas que, vendo o perigo para toda a paz futura a partir do crescimento do nazismo, defendeu a necessidade de fazer a guerra contra a Alemanha hitlerista.

57 PETTIT, 1997, p. 102. 
democracia onde a reflexividade resulta das interações lingüísticas entre os participantes e da formação holística das crenças.

Essa posição é pós-metafísica, ainda num outro sentido. As relações entre psicologia e política não são relações dedutivas, como se a descrição antropológica, que determina os sujeitos da ontologia social, fosse uma base independente, axiomática. Parece-me melhor, aqui, na perspectiva do equilíbrio reflexivo, analisar as relações entre psicologia e política - segundo uma certa interpretação possível de Rawls - como uma reconstrução daquilo que se deve pressupor para dar conta do funcionamento da democracia contemporânea. A definição do sujeito ou das pessoas não precede a compreensão social e política. Da mesma maneira que, em Rawls, a afirmação do caráter racional e razoável das pessoas não é uma descrição metafísica, mas uma reconstrução a partir do funcionamento das instituições políticas e jurídicas, pode-se pensar que a descrição de Pettit repousa sobre uma análise do comportamento social cotidiano das pessoas. Assim, falar das pessoas como "centros de pensamento, de sentimento e de ação" corresponde ao funcionamento real das instituições jurídicas ou políticas: sem essa pressuposição, não poderíamos entender o que está em jogo num debate parlamentar ou numa sessão de um tribunal.

$\mathrm{Na}$ terceira parte de The common mind, Pettit se interroga sobre as consequiências dessas teses sobre as concepções ou teorias sociais e políticas. Ele mostra que essas teses favorecem uma concepção republicana da liberdade individual. Para repetir: a diferença é que a liberdade republicana está ativamente garantida pelo aparelho político e jurídico da comunidade: ela consiste na garantia de não-dominação mais do que na simples ausência de interferência. O que me parece significativo, e que eu gostaria de apontar, seria, em primeiro lugar, que essas concepções implicam numa crítica aos modelos contratualistas e, mais geralmente, à insuficiência dos procedimentos democráticos concebidos como devendo produzir normas corretas. Da mesma maneira, implicam numa crítica ao comunitarismo. A democracia republicana é simultaneamente contestatória e deliberativa.

\section{Contratualismo, comunitarismo, republicanismo}

O conceito de liberdade negativa, como está construída pelos liberais, implica que as leis e as instituições políticas são apenas meios para permitir o exercício da liberdade, considerada esta como um valor absoluto. No 
limite, essa liberdade poderia ser exercitada no estado de natureza ou sob um regime monárquico. Certo, a liberdade republicana consiste também em ser protegido pela lei das interferências dos outros cidadãos. Essa liberdade, porém, implica, de maneira estrita, num conceito de igualdade, que não é uma idealização antropológica - como nas descrições do estado de natureza -, mas que corresponde à "condição de cidadania ou de igualdade diante da lei" ${ }^{58}$ Em outras palavras, a concepção liberal é "atomista", enquanto a concepção republicana é "holista". A tese republicana é que a concepção atomista (que considera um agente isolado) é incoerente. A tese holista afirma que não se pode conceber a liberdade senão no seio da sociedade: a liberdade é uma espécie de "estatuto social", só pode ser definida "comparativamente" ou "relacionalmente". ${ }^{99}$ Desse ponto de vista, "ninguém pode desfrutar perfeitamente da liberdade numa cultura dada (...) se ele está sujeito a mais coerções que os demais". ${ }^{60}$

Na medida em que a maioria das posições liberais se fundam sobre uma formulação ou outra da teoria do contrato social, o holismo permite mostrar que a fórmula do contrato se revela insuficiente para garantir uma liberdade como não-dominação. A doutrina do contrato é considerada por Pettit como permitindo muitos atos arbitrários. Pois ela é "a doutrina em que a liberdade de contrato significa a liberdade de decidir sobre os termos de um contrato e não a liberdade de aceitar ou recusar um contrato, em que o livre contrato legitima todo tratamento de um pelo outro que as partes concordam em aceitar". ${ }^{61}$

Desde que não precise tratar o "estado de natureza" como uma opção possível, não há razão de conceber a liberdade como uma propriedade não social. No nível político, isso significa que o consentimento não pode ser considerado como uma condição suficiente da legitimidade de um governo. Ainda mais, não pode ser considerado como uma condição necessária. Com efeito, na maioria dos casos, o que se chama de um consentimento democrático ou majoritário é um "consentimento tácito ou virtual", e a possibilidade de alcançar um consentimento real fica formal. Isso não significa uma recusa dos procedimentos representativos clássicos e das regras majoritárias. Significa, sim, que esses procedimentos não têm um valor absoluto e exclusivo, que eles não são necessariamente democráticos. 
A crítica do modelo contratualista poderia aproximar o republicanismo de Pettit do "humanismo cívico" ou mesmo de certas formas de comunitarismo, na medida em que o holismo poderia ser interpretado como uma tese não somente sobre o homem como ser naturalmente político, mas também sobre as determinações sociais fortes das atividades individuais. Sim, pode-se descobrir em Michael Sandel, Ronald Beiner ou Charles Taylor, argumentos "republicanos" para criticar o liberalismo. Eles defendem uma democracia participativa e um engajamento para com o bem comum. Mas é verdade que a maioria das posições comunitaristas são nostálgicas, anacrônicas e conservadoras. A crítica do liberalismo econômico se faz por um apelo a formas de vida política mais adaptadas a pequenas comunidades do que a sociedades modernas complexas. Nas sociedades pluralistas como as nossas, as posições comunitaristas justificam uma forma de paternalismo moral.

Como se sabe, o republicanismo pretende ser uma posição alternativa entre o liberalismo e o comunitarismo. Contra as posições comunitaristas, Pettit defende a sua concepção da liberdade negativa como não-dominação. Como o diz Bellamy,

\begin{abstract}
Desta maneira, a liberdade fica ligada à autolegislação, e não como o queriam as teorias da liberdade positiva e comunitaristas, em que os homens são seres políticos que podem realizar-se apenas participando de um certo tipo de comunidade, mas porque a única maneira de ter a garantia de não ser mandado arbitrariamente ou dominado por um outro é mandar-se a si mesmo. Em outras palavras, a motivação para identificar-se com a política e participar dela está baseada, antes, sobre uma forma de auto-interesse esclarecido do que sobre a virtude cívica per se. ${ }^{62}$
\end{abstract}

A descrição "psicológica" e as teses sobre o common knowledge podem então abrir o caminho para uma forma específica de democracia. Como diz Pettit, o modelo republicano tem parentesco com os modelos clássicos de democracia: insistência sobre a igualdade, o constitucionalismo, o controle ou a fiscalização do governo - aliás, com temas às vezes mais próximos de algumas idéias comunitaristas, como a idéia de comunidade ou de virtude cívica. Mas apresenta também idéias menos clássicas, uma vez que a concepção da democracia dá a precedência à fiscalização e contestação sobre o consenso. "Felizmente, um pouco de reflexão mostra que o que está exigido para a não arbitrariedade no exercício de um poder não é o consentimento atual a esse tipo de poder, mas a possibilidade permanente de contestá-lo efetivamente. ${ }^{63}$ 
Um dos fundamentos de tal proposição é exatamente a indeterminação intencional - a impossibilidade de fiscalizar a totalidade das decisões, de tal maneira que o funcionamento real de uma pessoa, de um grupo ou de um governo não pode ser previsto com precisão. É por isso que um regime "constitucional" - que parece a muitos liberais como o fundamento do estado de direito e como a garantia da aplicação da justiça - é imprescindível, mas não suficiente.

Por mais bem concebido que seja, todo sistema de direito deixará algumas decisões nas mãos de diferentes indivíduos e grupos. Os legisladores terão, evidentemente, poder sobre o conteúdo das leis, e a natureza problemática da interpretação jurídica significa que os administradores e os juízes serão obrigados a terem bastante liberdade quando da execução e aplicação das leis. ${ }^{64}$

Essa indeterminação pode ser interpretada como arbitrariedade e significa que a limitação da arbitrariedade se torna um problema essencial. Mas não é possível conjurar essa arbitrariedade com um sistema de prevenção - que seria necessariamente ligado a uma forma de planejamento e limitaria drasticamente a liberdade, como os liberais em geral o apontaram. A única possibilidade é a "contestação" a posteriori das decisões quando estimamos que não correspondem a nossos interesses ou à justiça. É por isso que "a democracia pode ser compreendida, sem forçar indevidamente nossas intuições, sobre um modelo que é primariamente contestatório antes de consensual". ${ }^{65}$ A essa necessidade de contestabilidade correspondem as "instituições formativas", como os controles (checks) e sanções jurídicas que são exigidos para estabelecer os direitos de liberdade, de imunidade e de seguridade, mas também uma maneira de organizar as coisas de tal forma que a pressão pública force os agentes a seguir uma certa orientação. Por exemplo, "o arranjo pelo qual os membros de um júri ou os jurados devem defender os seus votos diante dos outros membros faz pressão sobre eles para votar sobre a base de considerações publicamente confessáveis". ${ }^{66}$

\section{Uma democracia deliberativa}

Terminarei com uma nota sobre um tema bastante discutido hoje em dia em filosofia política: o ideal da democracia deliberativa. ${ }^{67} \mathrm{~A}$ democracia

67 BOHMAN; REHG, 1997; COHEN, 1989, p. 17-34; DRYZEK, 2000; MANIN, 1985, p. 72-93; MANIN, 1987, p. 338-368. 
republicana contestatória tem afinidades com a democracia deliberativa. Notemos, porém, uma diferença importante entre a teoria deliberativacontestatória de Pettit e aquela de Habermas e da maioria dos teoristas da democracia deliberativa. Habermas atribui às instâncias produtivas das normas (sociedade civil conectada com as instâncias legislativas) o papel fundamental de produção, através da elaboração deliberativa, da ordem jurídica. O executivo e o judiciário devem "aplicar" as normas, e não as contestar (o que pressupõe que o procedimento deliberativo foi correto) ${ }^{68}$ Para Pettit, o procedimento institucional pode ter sido até perfeito, mas, por motivos ligados à indeterminação, o papel de fiscalização a posteriori torna-se imprescindível. Nesse sentido, são as diversas formas de poder - e não somente o legislativo - que concorrem para produzir a ordem normativa.

Além dessa diferença, há vários elementos no republicanismo que convergem para a idéia de democracia deliberativa. ${ }^{69} \mathrm{O}$ republicanismo de Pettit favorece, na medida do possível, os procedimentos deliberativos, que correspondem à atividade reflexiva de seres pensantes cuja individualidade se forma na rede holística das conversações e intercâmbios discursivos. A forma deliberativa de tomada de decisão corresponde ao funcionamento normal das atividades sociais: inclusão, julgamento ponderado, dialogismo ${ }^{70}$ etc. O privilégio é dado à "deliberação" sobre a "negociação": na negociação cada um ou cada grupo defende seus interesses, fazendo o mínimo possível de concessões. Na deliberação, as partes tentam chegar a um acordo sobre os arranjos que respondem melhor às considerações que todas as partes podem reconhecer como pertinentes. "Na tomada de decisão baseada na negociação, as preferências estão dadas, na tomada de decisão baseada na deliberação, as preferências estão formadas." ${ }^{\prime 1}$

Porém - e isso é essencial -, da descrição do common mind não se pode deduzir um modelo institucional definitivo. Pettit mostra que o modelo da democracia deliberativa fica "seriously underspecified" e que várias questões dividem os defensores desse tipo de democracia: Quais são os contextos que devem ser democratizados (eleitorais, parlamentares, industriais, educacionais etc.)? Quais são as questões que devem ficar sob o controle democrático (a escolha dos funcionários, a definição dos programas políticos - em geral, ou

68 Cf. entre outros: HABERMAS, 2003.

69 Cf. PETTIT, 2001b.

70 A exigência dialógica "se aproxima das condições da fala ideal salientada por Jürgen Habermas" (PETTIT, 2001).

71 PETTIT, 1989, p. 187. 
em detalhe)? Em que medida o caráter democrático serve de legitimação às decisões? A nenhuma dessas questões pode se dar uma resposta conclusiva.

Além disso, como modelo da maneira dos grupos fazerem julgamentos e decisões coletivos, o ideal da democracia deliberativa, segundo Pettit, é inerentemente ambíguo. Pois a aplicação simples do modelo deliberativo aos procedimentos políticos enfrenta os paradoxos ou dilemas de decisão coletiva. Pettit remete ao "paradoxo doutrinal" de Kornhauser. ${ }^{72}$ É um paradoxo que surge quando um tribunal com vários membros deve tomar uma decisão na base de uma doutrina legal. Pode-se estender esse paradoxo fora do contexto jurídico. Pettit chama de "dilema discursivo" a forma mais geral das contradições que aparecem desde que é preciso "fazer julgamentos de grupos na base de razões". Não é o caso entrar aqui detalhadamente nas demonstrações de Pettit. Os paradoxos ligados às funções de escolha coletiva são conhecidos desde Condorcet e Arrow. ${ }^{73} \mathrm{O}$ interesse, na perspectiva de Pettit, é a tentativa não de criticar a idéia ou o ideal da democracia, mas de demonstrar que, em razão da racionalidade própria dos atores sociais e, portanto, dos cidadãos, nenhum dispositivo formal ou procedimental, tão necessário que seja, pode substituir a procura pelos indivíduos das melhores condições de exercício de sua liberdade.

\section{Referências Bibliográficas}

ARROW, Kenneth J. Social choice and individual value. $2^{\text {nd }}$ ed. New York: Wiley, 1963.

1951.

Social choice and individual value. New Haven: Yale University Press,

BELLAMY, Richard. Being liberal with republicanism's radical heritage. Res Publica. A Journal of Legal and Social Philosophy, Liverpool, v. 8, p. 269-274, 2002.

BERLIN, Isaiah. Two concepts of liberty. In: BERLIN, Isaiah. Four essays on liberty. Oxford: Oxford University Press, 1969. p. 122-134.

BERTEN, André. Republicanismo e motivação política. In: MERLE, Jean-Christophe; MOREIRA, Luiz (Ed.). Direito e legitimidade. São Paulo: Landy Livraria, 2003. p. 21-36.

72 KORNHAUSER; SAGER, 1993, p. 1-59. A questão formal dos paradoxos da decisão coletiva remete a Condorcet e a Arrow (entre outros).

73 Desde 1785, em "Essai sur l'application de l'analyse à la probabilité des décisions rendues à la pluralité des voix", Nicolas de Condorcet monstrava casos de intransitividade da maioria; esse teorema foi generalizado por Kenneth Arrow, mostrando que não existe uma função de escolha social indiscutível, função que permita a agregação das preferências individuais com as preferências sociais (ARROW, 1963). 
BIGNOTTO, Newton. Origens do republicanismo moderno. Belo Horizonte: Editora UFMG, 2001.

BIGNOTTO, Newton (Org.). Pensar a República. Belo Horizonte: Editora UFMG, 2002.

BOGDAN, Radu J. (Ed.). Mind and common sense. Cambridge: Cambridge University Press, 1991. . Interpreting minds. Cambridge: MIT Press, 1997.

BOHMAN, James; REHG, William (Ed.). Deliberative democracy. Cambridge: Harvard University Press, 1997.

BRAITHWAITE, John; PETTIT, Philip. Not just deserts. A republican theory of criminal justice. New York: Oxford University Press, 1990.

BRANSEN, Jan. Anthropocentrism within favourable circumstances. Inquiry, Sept. 1994.

BRANDOM, Robert B. Making it explicit. Reasoning, representing, and discursive commitment. Cambridge/London: Harvard University Press, 1994.

CHURCHLAND, Paul. Eliminative materialism and propositional attitudes. The Journal of Philosophy, v. 78, p. 67-90, 1981.

. A neurocomputational perspective. The nature of mind and the structure of science. Cambridge: MIT Press, 1989.

COHEN, Joshua. Deliberation and democratic legitimacy. In: HAMLIN, Alan; PETTIT, Philip (Ed.). The good polity. Normative analysis of the State. Oxford/New York: Basil Blackwell, 1989. p. 17-34.

CONSTANT, Benjamin. De la liberté des anciens comparée à celle des modernes. In: CONSTANT, Benjamin. De la liberté chez les modernes: écrits politiques. Paris: Livre de poche, 1980[1819]. p. 493-515.

DAVIDSON, Donald. Inquiries into truth and interpretation. Oxford: Oxford University Press, 1984.

DRYZEK, John S. Deliberative democracy and beyond. Oxford: Oxford University Press, 2000.

HABERMAS, Jürgen. Direito e democracia entre facticidade e validade. Tradução de F. B. Siebeneichler. Rio de Janeiro: Tempo Brasileiro, 2003.

HAMLIN, Alan; PETTIT, Philip. The normative analysis of the State: some preliminaries. In: HAMLIN, Alan; PETTIT, Philip (Ed.). The good polity. Normative analysis of the State. Oxford/New York: Basil Blackwell, 1989. p. 1-13.

HARRINGTON, James. The commonwealth of Oceana and a system of politics. Cambidge: Cambridge University Press, 1992.

JACKSON, Frank; PETTIT, Philip. Program explanation: a general perspective. Analysis, v. 50, p. 107-117, 1990.

KORNHAUSER, L. A.; SAGER, L. G. The one and the many: adjudication in collegial courts. California Law Review, v. 81, p. 1-59, 1993.

LARMORE, Charles. A critique of Philip Pettit's republicanism. NOUS, Philosophical Issues, v.11, p. 229-243, 2001. 
LARMORE, Charles. Liberal and republican conceptions of freedom. In: WEINSTOCK, D.; NADEAU, C. (Ed.). Republicanism: history, theory, and practice. London: Frank Cass, 2004. p. 96-119.

LEWIS, David. A philosophical study. Cambridge: Harvard University Press, 1969. . Philosophical papers. Oxford: Oxford University Press, 1986. v. 2.

MANIN, Bernard. Volonté générale ou délibération? Esquisse d'une théorie de la délibération politique. Le Débat, n. 33, p. 72-93, jan. 1985.

On legitimacy and political deliberation. Political Theory, p. 338-368, 1987.

PAPRZYCKA, Katarzyna. Collectivism on the horizon: a challenge of Pettit's critique of collectivism. Australian Journal of Philosophy, v. 76, n. 2, p. 165-181, Jun. 1998.

PETTIT, Philip. The freedom of the city: a republican ideal. In: HAMLIN Alan; PETTIT, Philip (Ed.). The good polity. Normative analysis of the state. New York: Basil Blackwell, 1989. p. 141-168.

. The common mind: an essay on psychology, society and politics. New York:

Oxford University Press, 1993.

Press, 1997.

Republicanism. A theory of freedom and government. Oxford: Clarendon

. Democracy's Discontent. The Journal of Philosophy, v. 95, n. 2, p. 73-96, Feb. 1998.

A theory of freedom: from psychology to politics. Cambridge: Polity Press, 2001a.

Deliberative democracy and the discursive dilemma. Philosophical Issues (Supp. Nous), v. 11, 2001b. PUF, 2004.

Penser en société. Essais de métaphysique sociale et de méthodologie. Paris:

POCOCK, J. G. A. Virtues, rights, and manners. Political Theory, v. 9, p. 353-368, 1981.

The machiavellian moment: florentine political theory and the atlantic republican tradition. Princeton: Princeton University Press, 1975.

PRICE, Huwe. The common mind: an essay on psychology, society and politics. Philosophy and Phenomenological Research, v. 55, n. 3, Sept. 1995.

QUINE, Williard van Orman. Where do we desagree? In: HAHN, Lewis E. (Ed.). The philosophy of Donald Davidson. Chicago: Open Court, 1999. p. 73-79.

RAWLS, John. O liberalismo político. Tradução de D. de Abreu Azevedo. São Paulo: Ática, 2000.

SKINNER, Quentin. Machiavelli on the maintenance of liberty. Politics, v. 18, p. 3-15, 1983.

. Liberty before liberalism. Cambridge: Cambridge University Press, 1998.

SPITZ, Jean-Fabien. La liberté politique. Paris: PUF, 1995.

SUNSTEIN, Cass R. After the rights revolution. Reconceiving the regulatory state.

Cambridge/London: Harvard University Press, 1990. 
TUOMELA, Raimo. In search for the common mind. A critical notice of Philip Pettit's The Common Mind. International Journal of Philosophical Studies, v. 2, p. 306-321, 1994.

VIROLI, Maurizio. Republicanism. New York: Hill and Wang, 2002.

WELLMAN, Henry M. The child's theory of mind. Cambridge: MIT Press, 1990. 